\title{
Leprosy: a 'common' and curable cause of peripheral neuropathy with skin lesions
}

\author{
${ }^{1}$ DP Breen, ${ }^{2} \mathrm{~J}$ Deeb, ${ }^{3} \mathrm{~S}$ Vaidya, ${ }^{4} \mathrm{DN}$ Lockwood, ${ }^{5} \mathrm{~A}$ Radunovic \\ ${ }^{1}$ Specialty Registrar in Neurology, National Hospital for Neurology and Neurosurgery, London, UK; ${ }^{2}$ Consultant Neurophysiologist, Queen's \\ Hospital, Romford, UK; ${ }^{3}$ Consultant Radiologist, Royal London Hospital, London, UK; ${ }^{4}$ Professor of Tropical Medicine, London School of \\ Hygiene and Tropical Medicine, London, UK; ${ }^{5}$ Consultant Neurologist, Queen's Hospital, Romford, UK
}

ABSTRACT Leprosy (or Hansen's disease) is a curable chronic infectious disease caused by the acid-fast bacillus Mycobacterium leprae. While leprosy remains one of the most common causes of neuropathy worldwide, its rarity in the UK means that many doctors are unfamiliar with the typical clinical features. This is problematic because early recognition and treatment is vital in order to minimise disease-related complications such as nerve injury. We describe a 75-year-old man who presented with multiple mononeuropathy (mononeuritis multiplex, particularly affecting the ulnar nerves) and typical granulomatous skin lesions, in whom the diagnosis was made on the basis of skin biopsy. We highlight the clinical features, investigations and treatment of the patient, and provide information about the epidemiology and pathogenesis of leprosy.

KEYWORDS leprosy, Mycobacterium leprae, neuropathy, Ridley-Jopling

DECLARATION OF INTERESTS No conflict of interest declared

\section{INTRODUCTION}

There has been a substantial reduction in the prevalence of leprosy over the last two decades, largely due to appropriate antimicrobial treatment and neonatal Bacillus Calmette-Guérin (BCG) vaccination. Nonetheless, leprosy remains an important disease globally with 230,000 cases diagnosed annually.' In comparison, only 129 new cases were reported in England and Wales between 200I-2010. ${ }^{2}$ This poses a diagnostic challenge for clinicians who may not have seen a case before. Doctors need to be aware of the clinical manifestations of leprosy, particularly when managing travellers or migrants from continents where leprosy is endemic.

\section{CASE HISTORY}

A 75-year-old, right-handed man presented with a 24-month history of progressive balance and walking difficulties. Over the previous six months, he had developed worsening weakness and clawing of the left hand. In recent weeks, he had also noticed mild clawing of the right hand and had begun dropping things. He described one stone weight loss over the last two years. There were no eye symptoms, joint pains or falls.

He was born in Nairobi, Kenya and spent his young adulthood in India. He moved to the UK in 1973 and returned annually to India for I-2 months (Surat, Gujarat state). He had no other travel history or exposure to infectious individuals.
Correspondence to DP Breen National Hospital for Neurology and Neurosurgery

33 Queen Square

London WCIN 3BG

UK

e-mail dpbreenI@gmail.com

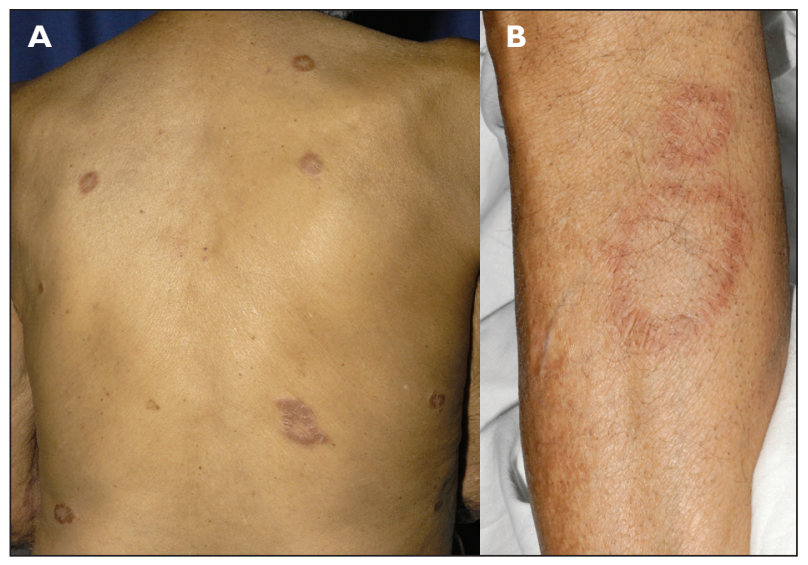

FIGURE I Skin lesions had a hypopigmented and mostly painless centre

On examination, he had more than 20 hyperpigmented skin lesions on his trunk, legs and arms (Figures IA and IB). There was no palpable peripheral nerve thickening. In the upper limbs, there was wasting of the first dorsal interossei and intrinsic hand muscles (worse on the left), as well as clawing of the left hand (Figure 2). He had no power in the ulnar and median supplied muscles of the left hand, and had global weakness elsewhere. Reflexes were brisk, Hoffman's reflex was negative, and sensation was normal. In the lower limbs, power was normal, reflexes were brisk, plantars were flexor bilaterally and vibration sense and pinprick sensation were reduced to the ankles bilaterally. He had an unsteady and slightly broad-based gait. Romberg's test was negative. There was no BCG vaccination scar. 
TABLE IA Nerve conduction studies - Sensory

\begin{tabular}{|l|l|c|c|c|c|}
\hline SENSORY & & & & & \\
\hline Nerve & Stimulating & Recording & Latency to onset (ms) & Amplitude (mV) & Velocity (ms) \\
\hline R. sural & Mid calf & Ankle & Absent & & \\
\hline R. superficial peroneal & Lower leg & Dorsal foot & Absent & & \\
\hline L. sural & Mid calf & Ankle & Absent & & 48 \\
\hline R. radial & Forearm & Thumb & 2.1 & 9.4 & \\
\hline R. median & 3rd digit & Wrist & Absent & & \\
\hline R. ulnar & 5th digit & Wrist & Absent & & \\
\hline L. radial & Forearm & Thumb & Absent & & \\
\hline L. median & 3rd digit & Wrist & Absent & & \\
\hline L. ulnar & 5th digit & Wrist & Absent & & \\
\hline
\end{tabular}

The sensory studies reflect the severity of the neuropathy, with responses obtained only from the right radial nerve.

TABLE IB Nerve conduction studies - Motor

\begin{tabular}{|c|c|c|c|c|c|c|}
\hline \multicolumn{7}{|l|}{ MOTOR } \\
\hline Nerve & Stimulation & Recording & $\begin{array}{l}\text { Latency to } \\
\text { onset }(\mathrm{ms})\end{array}$ & $\begin{array}{c}\text { Amplitude } \\
(\mathrm{mV})\end{array}$ & $\begin{array}{c}\text { Velocity } \\
\text { (ms) }\end{array}$ & $\begin{array}{c}\text { F. latency } \\
(\mathrm{ms})\end{array}$ \\
\hline R. common peroneal & \begin{tabular}{|l|} 
Ankle \\
Fib. head
\end{tabular} & EDB & $\begin{array}{l}5.2 \\
14.2\end{array}$ & $\begin{array}{l}2.2 \\
2.1\end{array}$ & 38 & 55 \\
\hline R. posterior tibial & Ankle & $\mathrm{AH}$ & 7.4 & 0.5 & & 51 \\
\hline L. common peroneal & \begin{tabular}{|l} 
Ankle \\
Fib. head
\end{tabular} & ADB & $\begin{array}{c}5.3 \\
14.3\end{array}$ & $\begin{array}{l}0.8 \\
0.2\end{array}$ & 38 & 57 \\
\hline R. median & $\begin{array}{l}\text { Wrist } \\
\text { Elbow }\end{array}$ & $\mathrm{AH}$ & $\begin{array}{c}4.5 \\
10.5 \\
\end{array}$ & $\begin{array}{l}2.4 \\
1.5 \\
\end{array}$ & 43 & 34 \\
\hline R. ulnar & $\begin{array}{l}\text { Wrist } \\
\text { Below elbow }\end{array}$ & ADM & $\begin{array}{l}4.1 \\
10.1 \\
\end{array}$ & $\begin{array}{l}1.5 \\
0.7\end{array}$ & 41 & 36 \\
\hline L. median & $\begin{array}{l}\text { Wrist } \\
\text { Elbow }\end{array}$ & $A B P$ & $\begin{array}{l}4.8 \\
11.0 \\
\end{array}$ & $\begin{array}{l}1.3 \\
0.6\end{array}$ & 42 & 38 \\
\hline L. ulnar & Wrist & ADM & Absent & & & \\
\hline
\end{tabular}

The motor studies indicate that i) there is a degree of asymmetry with reduced amplitudes on the left; ii) the ulnar nerves are particularly affected; iii) the pattern of nerve involvement is not length-dependant; iv) there is relative preservation of conduction velocities which is consistent with a predominantly axonal (rather than demyelinating) neuropathy.

Cervical cord pathology was initially considered in the differential diagnosis given the presence of brisk reflexes in his arms and legs, but no significant abnormalities were found on magnetic resonance scans of the brain and cervical spine. Instead, the man's presentation seemed to fit with a progressive neuropathy, with the ulnar nerves being particularly affected. Nerve conduction studies showed a severe, predominantly axonal, asymmetric, sensory-motor polyneuropathy affecting the upper and lower limbs (suggestive of multiple mononeuropathy or mononeuritis multiplex) (Tables IA and IB). Electromyography revealed severe chronic denervation potentials in all sampled muscles, as well as positive sharp waves in the left first dorsal interossei.

The next step was to identify the cause of his nerve pathology. In addition to leprosy, potential causes considered were lupus vulgaris, vasculitis, sarcoidosis,

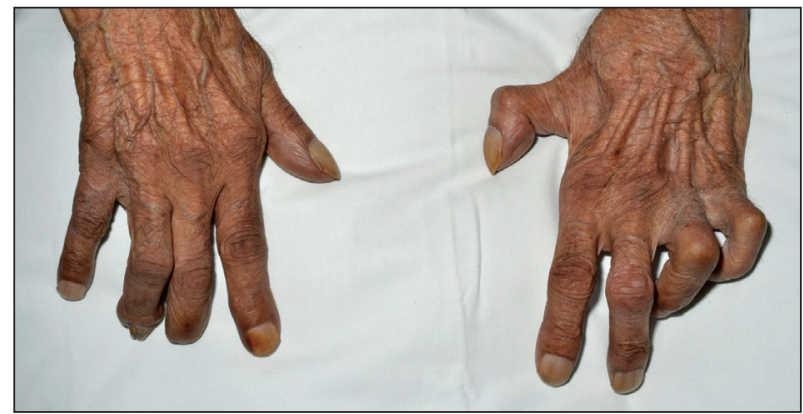

FIGURE 2 Examination revealed clawing of the left hand. The finger and hand deformities relate to previous occupational trauma rather than leprosy infection

amyloidosis, diabetes and connective tissue diseases. Blood tests revealed chronic renal impairment (urea 7.7 $\mathrm{mmol} / \mathrm{L}$, creatinine $133 \mu \mathrm{mol} / \mathrm{L}$ ), mildly raised serum 


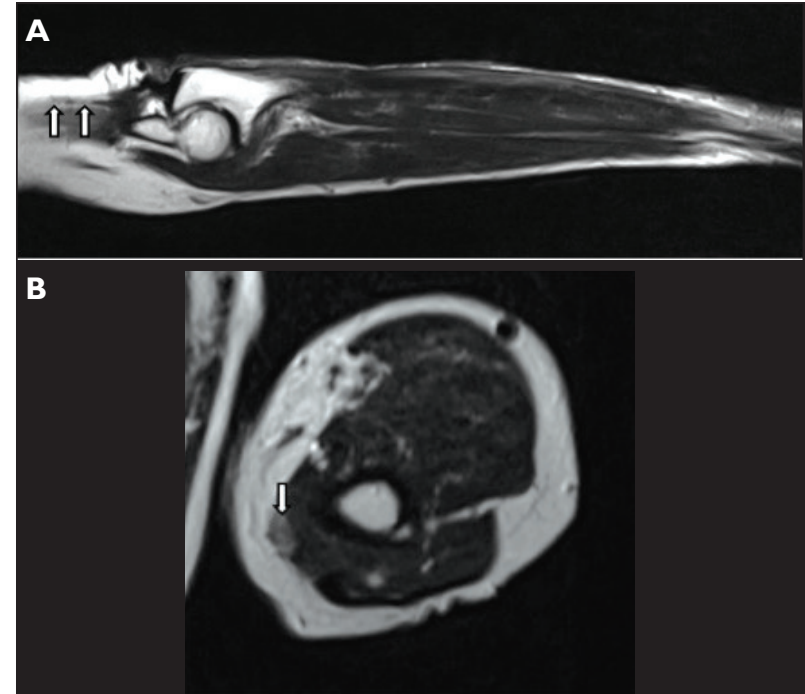

FIGURE 3 Magnetic resonance imaging of the upper limbs showed ulnar nerve thickening on saggital (A) and axial (B) T2 sequences

angiotensin converting enzyme level (74 U/L) and positive anti-nuclear factor (titre I/200, nucleolar pattern). The following tests were normal or negative: white cell count, erythrocyte sedimentation rate, liver function, bone profile, fasting glucose, creatine kinase, protein electrophoresis, immunoglobulins, complement, vitamin $\mathrm{BI}$, iron studies, folate, thyroid stimulating hormone, human immunodeficiency virus, hepatitis B surface antigen, hepatitis $C$ virus antibody, treponemal antibody, borrelia antibody, extractable nuclear antigen antibodies, anti-neutrophil cytoplasmic antibody, antiglomerular basement membrane antibody and paraneoplastic antibodies.

Cerebrospinal fluid analysis revealed no white blood cells, mildly raised protein $(0.48 \mathrm{~g} / \mathrm{L})$, normal glucose $(2.9$ $\mathrm{mmol} / \mathrm{L}$ compared to contemporaneous serum glucose $4.2 \mathrm{mmol} / \mathrm{L}$ ), no organisms and no malignant cells. There were matched oligoclonal bands in the cerebrospinal fluid and serum. Magnetic resonance imaging of the upper limbs revealed ulnar nerve thickening (Figures 3A and $3 B$ ).

Incisional biopsy of the thigh and punch biopsy of the abdomen (Figures 4A-C) showed non-necrotising epithelioid granulomas in the mid and deep dermis extending into subcutaneous fat and seen within damaged nerves. Acid-fast bacilli were identified on Wade-Fite staining. The granulomas had led to focal epidermal erosion with prominent oedema in some areas. Bacterial index was I (I-10 bacilli per 100 oil immersion fields). Overall, the features were felt to be in keeping with borderline tuberculoid leprosy.

The patient was referred to the Hospital for Tropical Diseases, University College London, where he was

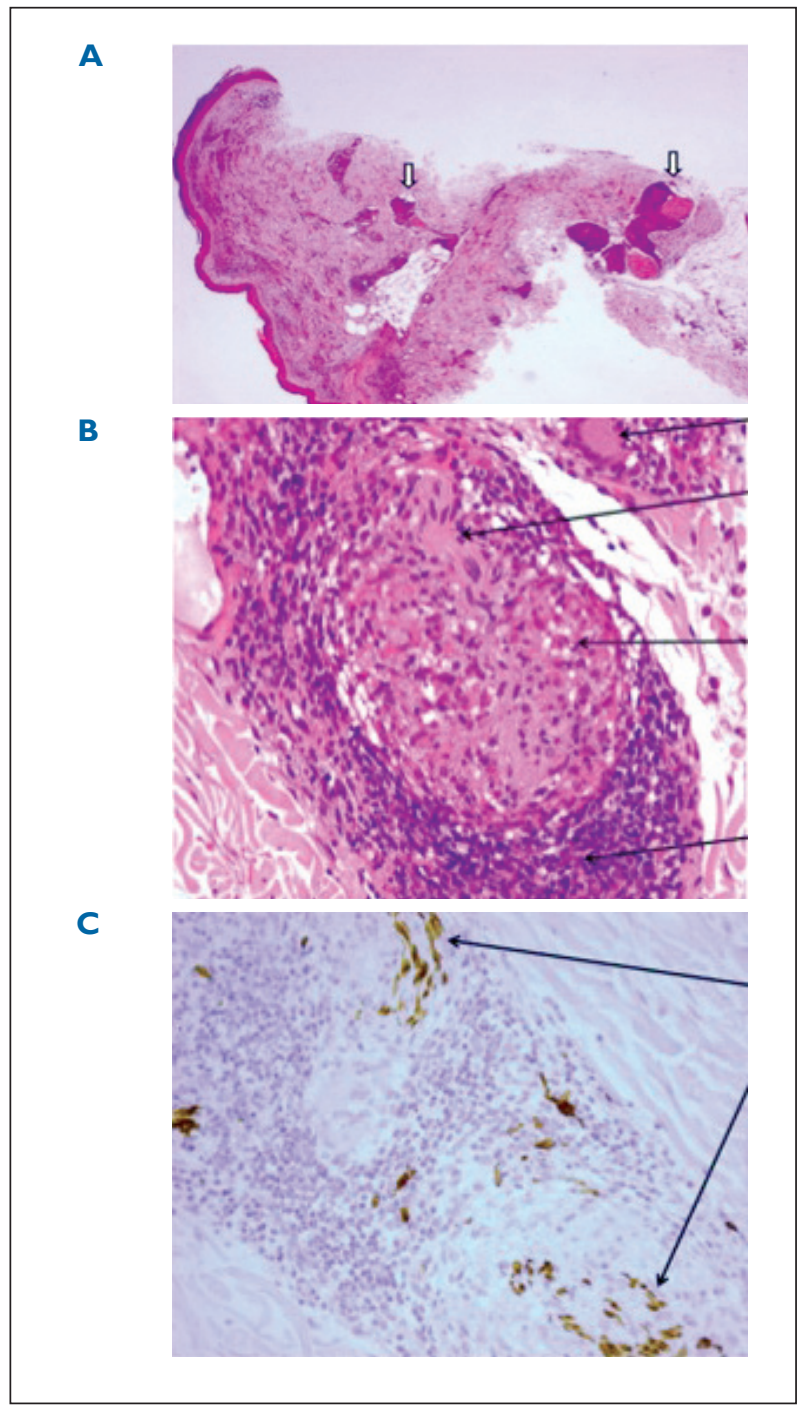

FIGURE 4 Biopsy revealed pan-dermal perineuro-vascular granulomas (A) with evidence of granulomatous neuritis (B) and loss of Schwann cells (C)

prescribed multi-drug treatment for 12 months (rifampicin $600 \mathrm{mg}$ monthly, $100 \mathrm{mg}$ dapsone daily and $50 \mathrm{mg}$ clofazimine daily). He was given a 6-month tapering steroid regimen, starting with $30 \mathrm{mg}$ prednisolone once daily. By the time he was reviewed in clinic three months later, the skin lesions had disappeared. Unfortunately, his late presentation meant that he was still significantly disabled due to his nerve damage.

\section{DISCUSSION}

Leprosy is a chronic infectious disease acquired when viable Mycobacterium bacilli are shed by an individual (probably by nasal secretions or skin contact). These bacteria are generally confined to parts of the body where the temperature is cooler (such as peripheral nerves). As they multiply slowly, they have the capacity to invade Schwann cells, after which the induced inflammatory 


\begin{tabular}{|c|c|c|c|c|c|}
\hline $\begin{array}{l}\text { WHO } \\
\text { Classification }\end{array}$ & \multicolumn{2}{|c|}{ Paucibacillary (PB) } & \multicolumn{3}{|c|}{ Multibacillary (MB) } \\
\hline $\begin{array}{l}\text { Bacteriological } \\
\text { Index }\end{array}$ & 0 & $0-1+$ & $1-3+$ & $3-5+$ & $5-6+$ \\
\hline Type of leprosy & $\begin{array}{l}\text { Polar } \\
\text { Tuberculoid }\end{array}$ & \multicolumn{3}{|c|}{ Borderline } & $\begin{array}{l}\text { Polar } \\
\text { lepromatous }\end{array}$ \\
\hline $\begin{array}{l}\text { Ridley-Jopling } \\
\text { Classification }\end{array}$ & $\pi$ & BT & BB & BL & LL \\
\hline Skin lesions & \multicolumn{5}{|c|}{ Increasing number of skin lesions } \\
\hline Nerve lesions & \multicolumn{5}{|c|}{ Increasing number of enlarged nerves \& nerve involvement } \\
\hline Stability & Stable & \multicolumn{3}{|c|}{$\begin{array}{l}\text { Unstable - may develop reactions and new } \\
\text { nerve damage }\end{array}$} & Stable \\
\hline
\end{tabular}

FIGURE 5 Classification and features of leprosy (@ Crown Copyright. Reproduced with permission of Public Health England ${ }^{2}$ )

infiltrate leads to damage of both myelinated and unmyelinated nerve fibres. This is followed by replacement of the peripheral nerve parenchyma by fibrous tissue.

Peripheral neuropathy is the main cause of morbidity in leprosy and can affect motor, sensory and autonomic nerves. Between $30-60 \%$ of patients will have nerve damage at the time of diagnosis. ${ }^{2}$ Patients often present with multiple mononeuropathy and certain patterns of nerve involvement are frequently observed. A previous study of 396 new leprosy cases found that the ulnar nerves were most commonly affected, both motor (20\%) and sensory components (I7\%). ${ }^{3}$ The same study found that the median sensory nerve was affected in $8.8 \%$ of cases. More recently, a Brazilian case series reported six leprosy cases presenting with isolated median neuropathy. ${ }^{4}$ Posterior tibial nerves are also frequently affected.

Although the diagnosis may be strongly suspected on clinical grounds, Public Health England advises that every leprosy case should be confirmed microscopically to define the subtype. ${ }^{2}$ The Ridley-Jopling classification is based primarily on the number of skin lesions and bacterial index, and reflects the degree to which the host is able to mount a cell-mediated immune response (Figure 5). In patients with tuberculoid leprosy, patients have high cell-mediated immunity characterised by well-demarcated skin lesions containing few bacilli; whereas those with lepromatous leprosy have more severely compromised host resistance and multi-system disease.
Patients with another leprosy subtype - pure neuritic leprosy - exhibit only neural signs and/or symptoms without clinically evident skin lesions. They usually require sensory nerve biopsy (including examination of the perineural skin tissues with appropriate microbiological staining) to establish the diagnosis. ${ }^{5}$ However, the classification of pure neuritic leprosy (and hence its treatment) remains a challenge because the number and distribution of affected nerves, immune response and nerve histology are not inter-related. ${ }^{6}$

Early recognition and diagnosis of leprosy is crucial to avoid lifelong disability. Where possible, UK patients should be transferred to the care of a Consultant Advisor in Leprosy in London, Liverpool or Birmingham. They provide expert advice regarding diagnosis, potential infectivity and management. Leprosy is a statutorily notifiable disease (the Health Protection Notification Regulations 2010 apply only to England). Treatment of leprosy involves multi-drug antimicrobial treatment for at least six months. Patients need to be followed-up regularly because immune-mediated complications can occur before, during or after treatment.

While leprosy is a treatable infection, many patients are left with irreversible neurological deficits (particularly if this is chronic due to delay in diagnosis or treatment). For this reason, education of medical staff about the presenting features of leprosy is crucial in order to improve patient outcomes. 


\section{KEY POINTS}

- Leprosy should be considered in any patient who has spent time in an endemic area and presents with signs of nerve damage or nerve thickening, skin lesions, or other typical clinical features (e.g. skin ulceration, erythema nodosum leprosum, orchitis and acute uveitis).

- Ulnar nerves are most commonly affected.

- Diagnosis should ideally be confirmed microscopically since treatment duration and prognosis depend on leprosy subtype.

- Multi-drug antimicrobial treatment is required for at least six months, with regular follow-up to detect any complications.

- Good clinical outcome relies on prompt detection and treatment of the infection, before significant nerve injury has occurred.

\section{REFERENCES}

I World Health Organization. Prevalence of leprosy. Available at http://www.who.int/lep/situation/prevalence/en/index.html (accessed 2/2/20I5).

2 Public Health England. Memorandum on leprosy 2012 on behalf of the Panel of Leprosy Opinion. London: Public Health England; May 20I3. https://www.gov.uk/government/publications/leprosymemorandum-20I2 (accessed 2/2/20I5).

3 Van Brakel WH, Khawas IB. Nerve damage in leprosy: an epidemiological and clinical study of 396 patients in west Nepal - Part I. Definitions, methods and frequencies. Lepr Rev 1994; 65 204-2I.

\section{ACKNOWLEDGEMENTS}

We would like to thank the patient for his permission to publish the case study. We are grateful to $\mathrm{Dr}$ Ula Mahadeva (Infectious Disease Histopathologist, St Thomas' Hospital, London); Dr Faisal Alyas (Consultant Radiologist, Queen's Hospital, Romford); and colleagues at the Department of Histopathology at Queen's Hospital, Romford, for their help in preparing the manuscript.
4 Vital RT, Illarramendi X, Antunes SL et al. Isolated median neuropathy as the first symptom of leprosy. Muscle Nerve 2013;48: 179-84.

5 Wilder-Smith E. Diagnosis of pure neuritic leprosy. Neurol J Southeast Asia 2002; 7: 6I-3. http://www.neurology-asia.org/ articles/20022_06I.pdf (accessed 2/2/20I5).

6 Kaur G, Girdhar BK, Girdhar A, et al. The clinical, immunological, and histological study of neuritic leprosy patients. Int J Lepr Other Mycobact Dis 1991; 59: 385-91. 